\title{
Analysis of total urinary catecholamines by liquid chromatography: methodology, routine experience and clinical interpretations of results
}

\author{
Erwin D. Schleicher ${ }^{\mathrm{a}, *}$, Frieder K. Kees ${ }^{\mathrm{b}}$, Otto H. Wieland ${ }^{\mathrm{a}}$ \\ ${ }^{a}$ Institut für Klinische Chemie, Stadt Krankenhaus Schwabing, Kölner Platz 1,8000 Munich 40 (FRG) and \\ ${ }^{b}$ Lehrstuhl für Pharmakologie, Universität Regensburg, Universitätstr. 31, 4800 Regensburg (FRG)
}

(Received July 12th; revision December 31st, 1982)

\section{Summary}

A simple routine method is described for simultaneous assay of total urinary adrenaline, noradrenaline and dopamine. The catecholamines are pre-purified on a small ion-exchange column, separated by reversed phase ion-pair liquid chromatography, and are quantitated by electrochemical detection. The method was routinely applied to 422 urines. Elevated values were found in four urine specimens obtained from patients with histologically proven phaeochromocytomas. Virtually no interference by endogenous or exogenous compounds was found. Values for urinary catecholamines determined by fluorimetric analysis agreed with those obtained by high pressure liquid chromatography with electrochemical detection. Within-day CV's for the compounds ranged from 5.2-11.9\%, between-day CVs from 3.3-6.6\%. The normal range ( $95 \%$ confidence level) was $20-230 \mu \mathrm{g} / 24 \mathrm{~h}$ for noradrenaline and $1-35 \mu \mathrm{g} / 24 \mathrm{~h}$ for adrenaline.

\section{Introduction}

The determination of urinary catecholamine excretion is useful in the diagnosis of phaeochromocytoma, neuroblastoma and in monitoring the treatment of these tumours. High pressure liquid chromatography (HPLC) has been proposed for the determination of adrenaline and noradrenaline after urinary extraction with $\mathrm{Al}_{2} \mathrm{O}_{3}$ [1], or boric acid gel [2], or a combination of both [3]. For detection UV-absorbtion [1], fluorescence [4,5], and electrochemical $[6,7]$ methods have been described. But these methods are not in common use, because they are either very tedious [3], or not sensitive enough [1,5].

* To whom correspondence should be addressed. 
We describe a method for the assay of urinary catecholamines using disposable columns pre-filled with a weak cation ion exchange resin for sample pre-purification. The catecholamines are eluted from the resin with boric acid and separated by HPLC. Detection is performed with an electrochemical detector. This analytical technique provides sensitivity, specificity and precision. The procedure has been applied to urine samples from hypertensive patients and appears to be free of interference by drugs, drug metabolites and endogenous compounds.

\section{Materials}

Noradrenaline, adrenaline and the kit for urinary catecholamine determination were obtained from Bio-Rad laboratories (Munich, FRG). Dihydroxybenzylamine (DHBA), di- $n$-butylamine and dopamine were from Sigma Chemical Co. (St. Louis, MO, USA). Octylsulfonate (PicB8) was purchased from Waters Associates (Milford, USA). All other chemicals were of analytical grade and were obtained from Merck (Darmstadt, FRG).

\section{Patients}

Patients were advised to discontinue all medication 2 days before urine collection. Patients followed no dietary restrictions except that no tea or coffee was allowed during urine collection.

\section{Methods}

\section{Urine collection}

Because of the paroxysmal nature of catecholamine secretion only 24 -h urine was analysed. The specimen was collected in a plastic container with $20 \mathrm{ml} 6 \mathrm{~mol} / 1 \mathrm{HCl}$ as stabilizer. After collection the volume was determined and an aliquot was removed for analysis. The aliquot was stored up to 4 weeks at $-20^{\circ} \mathrm{C}$ without the loss of catecholamine.

\section{Sample treatment}

$5 \mathrm{ml}$ urine were transferred to a $110 \times 30 \mathrm{~mm}$ plastic tube. After adjusting the $\mathrm{pH}$ to $0.5-1$ with $6 \mathrm{~mol} / 1 \mathrm{HCl}$ the urines were boiled in a water bath for $20 \mathrm{~min}$. Thereafter the $\mathrm{pH}$ was adjusted to 6.5 with $0.5 \mathrm{~mol} / \mathrm{/} \mathrm{NaOH}$ using a Dosimate 535 (Metrohm, Herisau, Switzerland), and the sample was poured into a column pre-filled with cation exchange resin ( $\mathrm{Na}$-form) with carboxylic acid exchange groups (Bio- $\mathrm{Rad}$ laboratories, Munich, FRG). After washing twice with $10 \mathrm{ml}$ water, the catecholamines were eluted with $8 \mathrm{ml}$ boric acid, $40 \mathrm{~g} / \mathrm{l}$.

For internal standardisation (not possible for fluorescence measurement) $0.5 \mathrm{ml}$ $10 \mathrm{mg} / 1$ DHBA was added to $5 \mathrm{ml}$ urine before sample treatment.

\section{Preparation of urine standards}

Pooled urine from normal persons was adjusted to $\mathrm{pH} 10$ with conc. $\mathrm{NH}_{3}$ to destroy endogenous free catecholamines. After standing for $3 \mathrm{~h}$ at $25^{\circ} \mathrm{C}$, the urine 
was acidified with $6 \mathrm{~mol} / 1 \mathrm{HCl}$ to $\mathrm{pH} 2$ and stored in 5 -ml portions at $-20^{\circ} \mathrm{C}$. Before use, adrenaline, noradrenaline and dopamine, were added to a $5-\mathrm{ml}$ sample to yield final concentrations of 200,200 and $500 \mu \mathrm{g} / 1$, respectively. Standards and blanks were analysed as described below and used for calculation of unknowns.

\section{Fluorescence analysis}

We determined total catecholamines in urine by the method of Sandhu and Freed [8] using the catecholamine kit from Bio-Rad according to the manufacturer's instructions. Fluorescence was measured with a Farrand spectrophotofluorometer (Kontron, Eching, FRG) at $520 \mathrm{~nm}$ with excitation at $405 \mathrm{~nm}$. Calculations were made by solving a simultaneous equation based on readings obtained from the standards. The concentration of dopamine was measured as described in [9].

\section{Liquid chromatographic analysis}

The high pressure liquid chromatography (HPLC) system consisted of a solvent delivery system $M 45$, an automatic sample injector WISP $710 \mathrm{~B}$ and a $5 \mu \mathrm{C}_{18}$ column RCM 100 (i.d. $8 \mathrm{~mm}$ ), all from Waters Associates (Milford, MA, USA). The electrochemical detector E 656/641 from Metrohm (Herisau, Switzerland) with a glassy carbon electrode was used. The detector potential was set at $0.8 \mathrm{~V}$ vs. an $\mathrm{Ag} / \mathrm{AgCl}$ reference electrode. The isocratic solvent consisted of a mixture of 5 vols. of $\mathrm{CH}_{3} \mathrm{OH}$ and 95 vols. of buffer of the following composition; $0.1 \mathrm{~mol} / 1$ sodium acetate, $20 \mathrm{mmol} / 1$ citric acid, $1 \mathrm{mmol} / 1$ dibutylamine, $0.1 \mathrm{mmol} / 1 \mathrm{EDTA}$ and 0.5 $\mathrm{mmol} / 1$ octanesulphonate. The buffer was filtered $(0.45 \mu \mathrm{m}$ Millipore filters) and degassed before use. The flow rate was set at $1.5 \mathrm{ml} / \mathrm{min}$ and $25 \mu \mathrm{l}$ of the boric acid eluate were injected. The peak height of unknown samples was compared with standards prepared as described above. When internal standard (DHBA) was used results were corrected for the loss during sample treatment.

Statistical analysis was performed by the Wilcoxon-test.

\section{Results and discussion}

The chromatogram of the urine from a normal person is shown in Fig. 1. The lack of interfering peaks allows determination of the catecholamines close to detection limits. Retention time and detection limits are listed in Table I. The calibration curves were linear up to $1000 \mu \mathrm{g} / 1$ for each analyte. The mean $( \pm S D)$ recoveries $(n=10)$ were as follows: noradrenaline $79.6 \pm 2.9 \%$, adrenaline $84.8 \pm 4.2 \%$, and dopamine $93.3 \pm 6.2 \%$. The means and the day-to-day CV's calculated from a 5-month period are shown in Table II together with the corresponding within-day CVs. In these studies, urinary catecholamines were determined with fluorescence and liquid chromatographic analysis without internal standard (interferes with fluorescence analysis). Urinary catecholamines of 24 normal persons were determined by HPLC and fluorescence analysis. The correlation of the two methods was $y=0.94 x$ $+4.2(r=0.986)$ for noradrenaline, $y=0.54 x+0.2(r=0.938)$ for adrenaline and $y=0.917 x-1.1(r=0.976)$ for dopamine. The two methods correlate fairly well, but 
TABLE I

DATA OF CATECHOLAMINE ANALYSIS BY HPLC

\begin{tabular}{|c|c|c|c|}
\hline \multirow[t]{2}{*}{ Compound } & \multirow{2}{*}{$\begin{array}{l}\text { Retention } \\
\text { time (min) }\end{array}$} & \multicolumn{2}{|c|}{ Detection limit * } \\
\hline & & $\begin{array}{l}\text { absolute } \\
\text { (pg) }\end{array}$ & $\begin{array}{l}\text { conc. } \\
(\mu \mathrm{g} / \mathrm{l})\end{array}$ \\
\hline Noradrenaline & 4.5 & 35 & 1.4 \\
\hline Adrenaline & 6.1 & 38 & 1.5 \\
\hline Dopamine & 12.1 & 70 & 2.8 \\
\hline DHBA & 7.8 & - & - \\
\hline
\end{tabular}

* Calculated for $25 \mu \mathrm{l}$ injection volume and for a detector sensitivity of $\mathrm{I} \mathrm{nA}$ at full scale.

Experimental conditions are described in the 'Method' section.

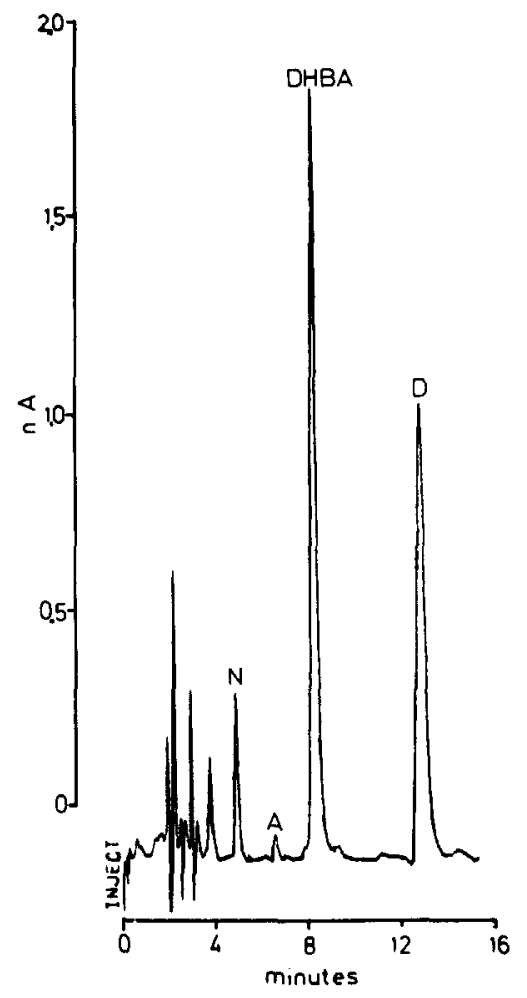

Fig. 1. Chromatogram of a urine sample from a normal person prepurified on a cation exchanger. $25 \mu 1$ were injected and separated on a $5 \mu \mathrm{C}_{18}-\mathrm{RCM} 100$ column. Electrochemical detection with electric potential set at $+0.8 \mathrm{~V}$. Solvent conditions and other details are described in the 'Methods' section. The catecholamine concentrations correspond to $20.7 \mu \mathrm{g} / 1$ noradrenaline (N); $3.7 \mu \mathrm{g} / 1$ adrenaline (A); 100 $\mu \mathrm{g} / 1 \mathrm{DHBA}$, and $101 \mu \mathrm{g} / \mathrm{l}$ dopamine (D). 
we found approximately half the adrenaline levels when determined by HPLC, which is in good agreement with [3].

Correlation of the fluorescence and HPLC data was not as good for catecholamine determination in urines from hypertensive patients, although patients that had not stopped with their drugs were eliminated (Fig. 2, A and B).

This suggests that minor amounts of drugs or drug metabolites may still have been present and interfered with the fluorescence analysis. Such an interference is described for $\alpha$-methyldopa in the literature [10]. In our studies treatment with $\alpha$-methyldopa $(250 \mathrm{mg} /$ day) resulted in two extra peaks, probably metabolites of $\alpha$-methyldopa which appeared after dopamine and did not interfere with the assay. We found that Fenistil ${ }^{\circledR}$, an antihistaminic drug, and Trandate ${ }^{\circledR}$ also interfere with fluorimetric but not HPLC analysis. This was shown with urines to which these drugs were added before sample treatment, and also with urine from patients undergoing therapy with these drugs. Accordingly, the following drugs were found not to interfere analytically with the described method: allopurinol, aspirin, caffeine, clonidine, dihydralazine, digoxin, indometacin, insulin, nitrofurantoin, prazosin, propanolol, quinidine, reserpine, thyroxine. We have now analysed 422 urine samples from hypertensive patients, most of them not omitting drugs before urine collection, and no interference with the HPLC catecholamine determination could be seen. It appears that the combination of ion exchange chromatography, reversedphase chromatography and electrochemical detection lowers errors due to drug interference.

Data on catecholamine excretion of four patients with phaeochromocytoma are given in Table III. The diagnosis of phaeochromocytoma was confirmed by histological examination of tissues removed at surgery. Noradrenaline excretion was greatly increased in all cases with fairly good agreement of the results obtained by either fluorescence- or HPLC determination. In contrast, adrenaline measurements

\section{TABLE II}

\section{PRECISION OF THE CATECHOLAMINE ASSAY}

The determination of urinary catecholamines was performed by HPLC with amperometric detection as described in the 'Method' section. The within-run (A) and day-to-day (B) precisions are shown.

\begin{tabular}{|c|c|c|c|c|c|c|c|c|}
\hline & & \multirow[t]{2}{*}{$n$} & \multicolumn{2}{|c|}{ Noradrenaline } & \multicolumn{2}{|c|}{ Adrenaline } & \multicolumn{2}{|c|}{ Dopamine } \\
\hline & & & $\begin{array}{l}\text { mean } \\
(\mu \mathrm{g} / \mathrm{l})\end{array}$ & $\begin{array}{l}\mathrm{CV} \\
(\%)\end{array}$ & $\begin{array}{l}\text { mean } \\
(\mu \mathrm{g} / \mathrm{l})\end{array}$ & $\begin{array}{l}\mathrm{CV} \\
(\mathscr{6})\end{array}$ & $\begin{array}{l}\text { mean } \\
(\mu \mathrm{g} / \mathrm{l})\end{array}$ & $\begin{array}{l}C V \\
(9)\end{array}$ \\
\hline \multirow[t]{2}{*}{ Level 1} & A & 20 & 28.8 & 8.0 & $*$ & & 131 & 2.6 \\
\hline & B & 20 & 28.6 & 12.2 & $*$ & & 135 & 8.2 \\
\hline \multirow[t]{2}{*}{ Level 2} & A & 20 & 307 & 3.3 & 51.0 & 6.6 & 255 & 4.1 \\
\hline & B & 21 & 301 & 6.5 & 49.4 & 11.9 & 248 & 5.2 \\
\hline \multirow[t]{2}{*}{ Level 3} & A & 20 & 135 & 3.3 & 10.6 & 13.8 & 393 & 1.9 \\
\hline & B & 20 & 135 & 4.0 & 9.6 & 30.4 & 346 & 3.0 \\
\hline
\end{tabular}

- Value below detection limit. 

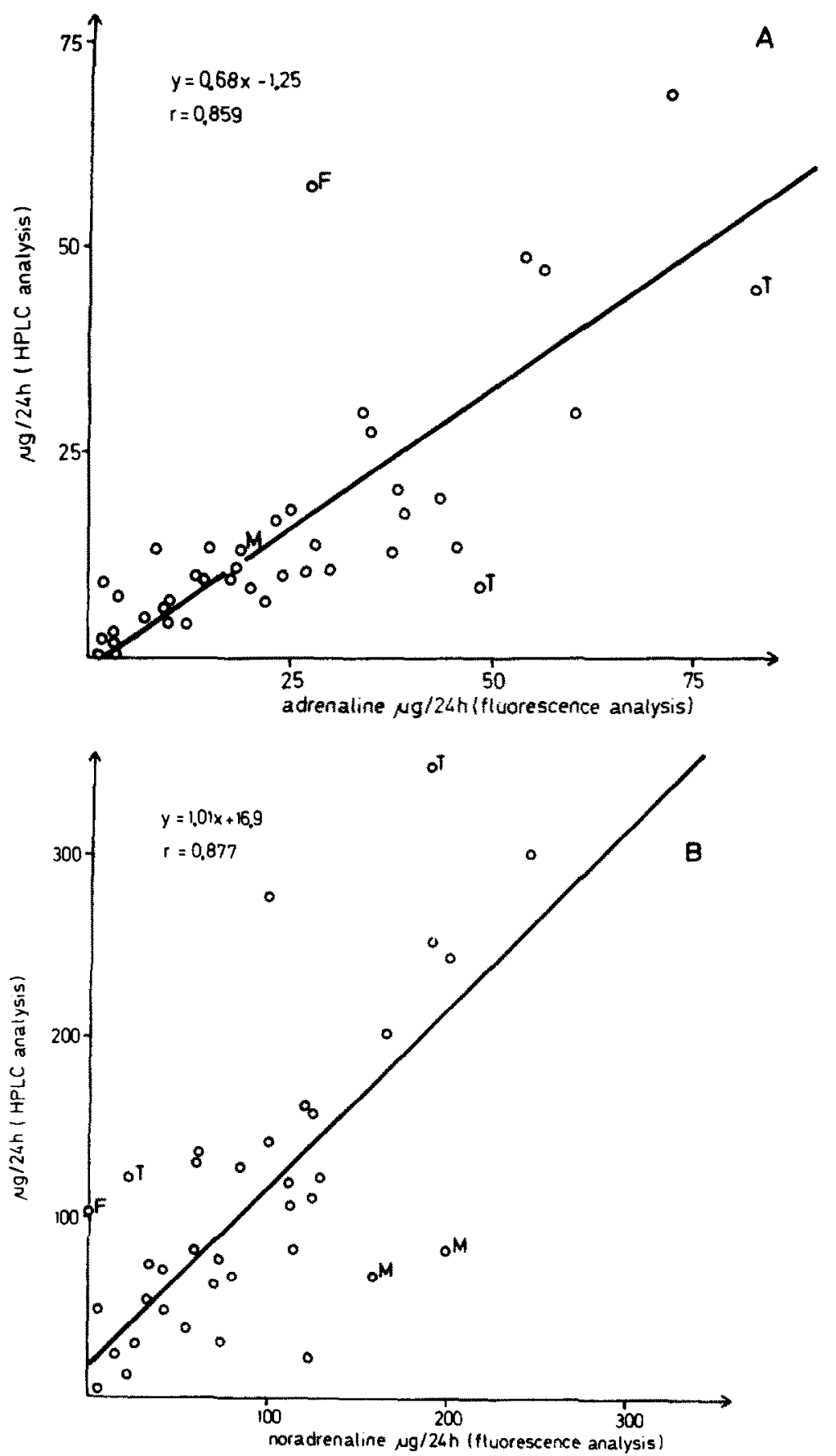

Fig. 2. Correlation of the daily excreted amounts of urinary adrenaline (A) and noradrenaline (B) from hypertensive patients determined either by fluorescence analysis or by liquid chromatography $(n=37)$. Values marked with $M, T$ and $F$ are urines from patients receiving Methyldopa ${ }^{\star}$, Trandate ${ }^{\star}$, and Fenistil $^{*}$, respectively. 


\section{TABLE III}

URINARY CATECHOLAMINE EXCRETION OF NORMAL PERSONS AND PATIENTS WITH PHAEOCHROMOCYTOMA

The $95 \%$ confidence range for a collective of normal persons $(n=64)$ was $20-230 \mu \mathrm{g} / 24 \mathrm{~h}$ for noradrenaline and $1.0-35 \mu \mathrm{g} / 24 \mathrm{~h}$ for adrenaline.

\begin{tabular}{|c|c|c|c|c|}
\hline \multirow[t]{2}{*}{$\begin{array}{l}\text { Patient } \\
\text { No. }\end{array}$} & \multicolumn{2}{|c|}{$\begin{array}{l}\text { Noradrenaline } \\
(\mu \mathrm{g} / 24 \mathrm{~h})\end{array}$} & \multicolumn{2}{|l|}{$\begin{array}{l}\text { Adrenaline } \\
(\mu \mathrm{g} / 24 \mathrm{~h})\end{array}$} \\
\hline & fluorescence & HPLC & fluorescence & HPLC \\
\hline$\overline{1}$ & 720 & 966 & 57 & 456 \\
\hline 2 & 2251 & 2569 & 49.9 & 18.9 \\
\hline 3 & 2450 & 2218 & 50.0 & 2 \\
\hline 4 & 2879 & 2600 & 266 & 377 \\
\hline
\end{tabular}

Analytical details are described in the 'Method' section.

yielded variable results with both methods. The reason for this discrepancy is not clear. Fourteen days after removal of the tumour, the urinary catecholamine levels were found to be normal.

Age-dependent reference values for both, free and total adrenaline, noradrenaline, and dopamine are currently determined in our laboratory and will be published elsewhere.

In conclusion, the described method offers an accurate, precise catecholamine assay free of drug interference which is associated with the fluorimetric assay. In addition, the electrochemical detection is highly specific and more sensitive than the fluorimetric detection that has been described $[4,5]$. The speed and reproducibility at sample pre-purification make this catecholamine assay highly suitable for clinical use.

\section{Acknowledgement}

We wish to thank $H$. Aigner for helpful discussion and for solving separation problems.

\section{References}

1 Mell LD, Gustafson AB. Urinary free norepinephrine and dopamine determined by reverse-phase high-pressure liquid chromatography. Clin Chem 1977; 23: 473-476.

2 Higa S. Suzuki T, Hayashi $A$ et al. Isolation of catecholamines in biological fluids by boric acid gel. Anal Biochem 1977; 77: 18-24.

3 Moyer TP, Jian NS, Tyce GM, Sheps SG. Analysis for urinary catecholamines by liquid chromatography with amperometric detection. Methodology and clinical interpretation of results. Clin Chem 1979; 25: $256-263$.

4 Jackman GP. Differential assay for urinary catecholamines by use of liquid chromatography with fluorometric detection. Clin Chem 1981; 27: 1202-1204.

3 Anderson $\mathbf{G M}$, Young JG, Jathow PI, Cohen DJ. Urinary free catecholamines determined by liquid chromatography fluorometry. Clin Chem 1981; 27: 2060-2063. 
6 Riggin RM, Kissinger PT. Determination of catecholamines in urine by reverse-phase liquid chromatography with electrochemical detection. Anal Chem 1977; 49: 2109-2111.

7 Oka K, Sekiya M, Osada H, Fujita K, Kato T, Nagatsu T. Simultaneous fluorometry of urinary dopamine, norepinephrine, and epinephrine compared with liquid chromatography with electrochemical detection. Clin Chem 1982; $28: 646-649$.

8 Sandhu RS, Freed RM. An improved method for the determination of urinary catecholamines. Clin Chem 1968; 14: 824-825.

9 Routh JI, Bonnow RE, Fincham RW, Stoll JL. Excretion of L-Dopa and its metabolites in urine of Parkinson's disease patients receiving L-Dopa therapy. Clin Chem 1971; 17: 867-871.

10 Werner U. Verbesserte Trihydroxyindolmethode zur Bestimmung der Harnkatecholamine. Z Klin Chem Klin Biochem 1975; 13: 341-349. 